\title{
Reproductive Health Knowledge, Attitude and Practice Among Adolescents Attending Secondary Schools in Asmara, Eritrea
}

\section{Yonatan Mehari Andemeskel (D Yonimer2@gmail.com )}

Orotta College of Medicine \& Health Sciences https://orcid.org/0000-0003-1772-1042

\section{Ghidey Gebreyohannes Weldegiorgis}

Orotta College of Medicine \& Health Sciences

\section{Bekit Zere Bekit}

Massawa Zonal Referral Hospital, Eritrea

\section{Ermias Gebregziabiher Gebresilassie}

Orotta Medical Surgical National Referral Maternity Hospital, Eritrea

\section{Goitom Hagos Gebreab}

Orotta Medical Surgical National Referral Maternity Hospital, Eritrea

\section{Tedros Yemane Gebresilassie}

Orotta Medical Surgical National Referral Maternity Hospital, Eritrea

\section{Yonas Haile Abraha}

Orotta Medical Surgical National Referral Maternity Hospital, Eritrea

\section{Research}

Keywords: Adolescent, Attitude, Knowledge, Practice, Reproductive health

Posted Date: October 18th, 2021

DOl: https://doi.org/10.21203/rs.3.rs-958951/v1

License: (9) (i) This work is licensed under a Creative Commons Attribution 4.0 International License. Read Full License 


\section{Abstract}

Background: Adolescent reproductive health problems are a great threat to adolescent's warfare and such problems are associated with inadequate knowledge. In Eritrea, as adolescent reproductive health is not given much attention the knowledge is expected to be poor, which could lead adolescents to become victims of adolescence related reproductive health problems and limit their opportunity to build a better future. Therefore, this study was carried out with the aim of investigating the reproductive health knowledge, attitude and practice among secondary school students in Asmara, the capital of Eritrea.

Methods: A cross sectional study design was conducted on 428 adolescent high school students with the age range of 14 to 19 years. Sample size was determined by using a single population proportion formula. Initially, population size of each school and each grade was taken and proportional sample size was determined from each school and then from each grade. The list of students was used and participants were selected using simple random sampling. Data was collected through a structured selfadministered questionnaire. Descriptive and inferential analysis were made using SPSS (version 22). Statistical significance level was set at $P<0.005$.

Results: The median age of the study participants was 15 (IQR=2), in which $88.8 \%$ were between age of 14 to 16 years with $53 \%$ of them being females. The level of knowledge of the students regarding RH was low, with moderate to good attitude. Sexual practice was very low (3.5\%) with usage of $86.7 \%$ of contraceptive use. Meanwhile, the usage of sexually explicit material was relatively higher (53\%).

Conclusions: Reproductive health knowledge was low almost in all variables. Meanwhile, significant number of students are already engaged in heterosexual romantic relationships and use of sexually explicit material. Adolescents need to be knowledgeable about themselves and the people they relate to, need sound information about the physical, psychological and social changes that take place through childhood to adolescence.

\section{Introduction}

Adolescence is a challenging phase of life, within which the individual attains physical, sexual and social maturity. It is difficult to define which factors influence adolescent risk-taking and health-seeking behavior, since multiple risk-related factors operate at individual, family, community and societal level to play important contributions [1]. This period is a dramatic challenge, one requiring adjustment to changes in the self, in the family, and in the peer group, requiring individuals to make concurrent regulations in relation with the complex and changing context which would serve as a key factor for a successful development across life [2]. The most distinct adolescent behavioral changes include increased risk taking, increased sensation seeking, and a move away from parent towards a greater peer affiliation [3]. Adolescent reproductive health problems are still a great threat to adolescent's welfare. It has been discovered that the main source of adolescents' reproductive health problem is inadequate knowledge on 
reproductive health. This limits adolescents' opportunity to build their future as they find themselves victims of early pregnancy, HIV/AIDS, sexually transmitted infections and early marriage $[4,5]$.

The opportunity that can be used to shape adolescents' health behaviour positively is, the highly adaptive feature of their brain for its ability to change in response to the demands of the environment [3]. School and family environment play a dominant role in the behavior of adolescents. It has been long proved that optimal adolescents' development occurs among those who have family support and supportive school environment [6]. However studies proved that adolescent-family discussion about sexual and reproductive health issues in Eastern Africa is a taboo and avoided resulting in the highest rates of adolescent unplanned pregnancy in the region [7-10]. Overall, peer socialization, parent-child relationship, parental supervision and parental values are consistently associated with the riskiness of sexual behaviours and age of sexual initiation [11].

Adolescents in the Sub-Saharan region lack knowledge about STIs and face greater barriers in accessing available services $[7,12]$. Moreover, their vulnerability to poor sexual reproductive health is compounded by the lack of availability of, and access to, youth-friendly services and health products as well as by insufficient, inaccurate, or complete lack of knowledge and information about safe sex and contraceptive use [13]. Eritrea, a country in the horn of Africa, the younger age groups (19 years and below) comprise the larger proportion of the population, consisting $47.7 \%$ and those $10-19$ year olds cover $28 \%[14,15]$. More than a quarter (28\%) of all the secondary school students in the capital city, Asmara fall in the age groups of 14 to 18 years. Similar to other adolescents worldwide, adolescents in Eritrea use their second decade of life in a transitional period whereby they are exposed to too many risks and become vulnerable to problems that can have a long term impact on their lives. In a previous pre and posttest interventional type of study which was conducted among female students in the southern region of the country the comprehensive knowledge regarding reproductive health was observed to be low [16]. Moreover, according to the national surveys conducted, the comprehensive knowledge on HIV and sexually transmitted infections, mode of transmission, signs and symptoms and prevention methods was also below $10 \%[17,18]$. Generally, adolescent reproductive health has not been given much attention. Early sexual initiation without having adequate information and services is on the rise in the country, comprising $15 \%$ and $21 \%$ in adolescent women and men respectively with great variations among regions [19], which puts this age group at a greater risk. Being the larger segment of the population therefore makes it important to invest on the health and well-being of adolescents for the current and future well-being of the Eritrean society.

Nevertheless, preparing these young people for the transition to adulthood, a time when sexuality and relationships are central, is challenging. Most adolescents find themselves in critical health status due to ignorance or possession of inadequate or improper knowledge on reproductive health $[13,20,21]$. It is important for adolescents to have universal access to comprehensive SRH information and services that are evidence based, confidential, developmentally appropriate, and culturally sensitive. To act on those needs adolescent should be equipped with relevant knowledge so as to enhance reproductive health and avoid reproductive health related problems. Thus the purpose of this study is to assess the current 
reproductive health behavior (knowledge attitude and practice) and sexual behavior of adolescent secondary school students in Asmara city and come up with age appropriate recommendation for intervention strategies.

\section{Methods}

\section{Study Design and study setting}

The study utilized a quantitative descriptive cross-sectional study design between September 2018 and January 2019 in the secondary schools of Asmara. The capital city is situated in Maekel region with a population of 804,000 in a $45 \mathrm{~km}$ square at an elevation of 2,325 meter above sea level. There are eleven secondary schools within thirteen administrative areas with a total of 19,918 student population [22].

\section{Study Participants}

Secondary school students studying in grade nine, ten and eleven with an age range of 14 to 19 years were included in the study. Students who were willing were include in the study.

\section{Sample and Sampling Method}

Sample size was determined by using a single population proportion formula that is: $n_{1}=z^{2} p(1-p) / e^{2}$, Where, $[Z=$ confidence interval $(1.96), p=$ proportion of the students who have adequate knowledge, attitude, and practice (0.5), e= margin of error (0.05)]. The initial sample size was found to be 385 . Considering the non-response rate, $(r=0.90)$, the final sample size for the study was 428 . Initially, population size of each school and each grade was taken and proportional sample size was determined from each school and then from each grade. The list of students was used as a sampling frame and participants were selected using simple random sampling.

\section{Data collectiontool and method}

A structured self-administered questionnaire was used to collect data. The questionnaire was initially developed by Ghidey et al., (2015), and utilized to assess the reproductive health knowledge among high school students[16]. The questionnaire was thoroughly revised for its relevance and quality by public health and nursing experts. The first section comprises the key elements of socio-demographic details of the students including the age, educational level, family background, social media usage. The second section assesses their knowledge, attitude and practices of reproductive health of the adolescent students.

\section{Data collection procedure}

Permission for conducting the research was initially obtained from the ethical and scientific committee of Asmara College of Health Sciences and that of the Ministry of Health. Moreover, permission was secured at all levels of relevant offices of the Ministry of Education and from the director of each high 
school. Prior to data collection the schools were visited, dates for data collection were set together with the school directors. The purpose of the study was explained to the study participants and they were told that their participation is voluntary and they can withdraw at any time. After assuring their participation, participants were asked for their written consent before administering the questionnaire. For those who were under the age of 18 years, consent was obtained from their guardian Data was collected using assisted self-administered questionnaire. Participants were assisted in case they require clarification and to reduce errors in understanding or misinterpreting the questions. Questionnaires were coded and no individual information was included in the questionnaire, thus confidentiality and data security was maintained throughout the research process. Each of the questionnaires was promptly checked for completion and for any correction before leaving the data collection site.

\section{Variable Measurement}

Three components namely, knowledge, attitude and practice of the students were measured with regard to reproductive health. The component 'knowledge' involves thirteen items with a score ranging between zero and thirteen. Higher values indicate increased level of knowledge. A total of eight items were identified to assess the respondents' 'attitude'. The items were initially prepared in a five point Likert scale ranging from 'strongly agree' (score=1) to 'strongly disagree' (score=5). The responses were reclassified and the responses 'strongly agree', 'agree', and 'neutral' were considered as 'agree' whereas 'disagree' and 'strongly disagree' as 'disagree'. Moreover, the overall attitude of the respondent toward reproductive health was also measured. A composite score was constructed form the eight items with a minimum value of eight and maximum of forty. Increased score indicates a decrease in positive attitude. Regarding the component 'practice', ten items assessed the practice towards reproductive health. The scores were zero (no practice) and one (there occurred practice). The questionnaire was pretested in secondary schools outside Asmara and necessary amendments were done before use as to fit the study objectives, setting and population.

\section{Data Processing and analysis}

Data was entered into SPSS (version 22) for analysis. Data cleaning and preliminary explorations were done before conducting the main analysis. Frequency, percent, mean (SD), and median (IQR) were used to make descriptive analysis, as appropriate. Comparisons of the knowledge and attitude across categories of student characteristics were done using independent samples t-test and one way ANOVA (LSD post hoc) whereas, comparisons in practice across was done using Mann-whitney $U$ test and Kruskal Wallis test. Tables and figures were used to present the results. $P$-values less than 0.05 were considered as significant throughout the analysis.

\section{Results}

\section{Demographic Characteristics}


The median age of the study participants was 15 (IQR=2), in which $88.8 \%$ were between age of 14 to 16 years. Of all the study participants, $53 \%$ were females. Grade composition include $178(41.6 \%)$ grade nine, $142(33.2 \%)$ grade ten and $108(25.2 \%)$ grade eleven. The majority $(91.8 \%)$ of the respondents were Christians and the rest $8.2 \%$ were Muslims. Regarding their family status, $71.5 \%$ live with both parents (father and mother), whereas $18.5 \%$ live with their mother only, and the rest $10 \%$ without any of the parents. The majority (91.8\%) belong to Tigrigna ethnic group. With regard to the educational background of their parents, $81.5 \%$ fathers and $77.8 \%$ mothers of the students completed junior level or above, whereas illiterate parents were less than $9 \%$. Students who discussed on important issues with their family were 396 (92.5\%), but only 107 (25\%) discussed about sexual issues and 225 (52.6\%) discussed about pubertal changes during adolescence. The socio-demographic characters of the study participants is available as additional file 1 .

\section{Knowledge of participants on human reproductive system}

The majority $(n=219,51.2 \%)$ of the respondents stated testes as an important reproductive organ, followed by ovary (47.2\%), don't know (24.8\%); penis (19.4\%); vagina (17.3\%) and bladder $(8.2 \%)$. Participants who knew the age of menarche were 227(53\%) and those who correctly described the average days of menstrual cycle were 137 (32\%). Participants were also asked the time of conception during menstrual cycle, and $69(16.1 \%)$ replied correctly (Table 1).

Table 1.Study participants' knowledge about human reproductive organs and function. 
Important male/female reproductive organ

\begin{tabular}{lll}
\hline Penis & 83 & 19.4 \\
\hline Vagina & 74 & 17.3 \\
\hline Bladder & 35 & 8.2 \\
\hline Testes & 219 & 51.2 \\
\hline Ovary & 202 & 47.2 \\
\hline I don't know & 106 & 24.8 \\
\hline
\end{tabular}

At what Age menarche starts

\begin{tabular}{|lll|}
\hline 13 to 16 & 227 & 53 \\
\hline Other incorrect response & 201 & 47 \\
\hline Average days of menstrual cycle & & \\
\hline 28 & 137 & 32 \\
\hline Incorrect response & 291 & 68 \\
\hline Days a woman can conceive during menstrual cycle & & \\
\hline Mid cycle & 69 & 16.1 \\
\hline Other incorrect response & 359 & 83.9 \\
\hline
\end{tabular}

\section{Knowledge of participants about STls}

As presented in table 2, the percentage distribution of responses of the students regarding sexually transmitted infections were HIV/AIDS (95.3\%), syphilis (25\%), gonorrhoea (21.3\%), herpes simplex (9.8\%), hepatitis B (4.4\%), and I don't know (3.3\%). Most (44.6\%) of the students responded that they don't know the signs and symptoms of STI, those responded as high grade fever (31.8\%), genital ulcer (31.6\%), foul smelling discharge (26.2\%), and no sign (7.9\%). More than three fourth $(77.3 \%)$ of the students responded unprotected sex as a mode of transmission of STIs. Others responses include contaminated blood (53.5\%), MTCT (52.3\%), and unsterilized sharps (49.3\%). Very few (6.8\%) were found to have no knowledge of the modes of transmission.

Table 2. Percentage distribution of study participants on knowledge of STI. 
Most common sexually transmitted infections

\begin{tabular}{lll}
\hline Gonorrhea & 91 & 21.3 \\
\hline Hepatitis B & 19 & 4.4 \\
\hline Syphilis & 107 & 25 \\
\hline Herpes simplex & 42 & 9.8 \\
\hline HIV/AIDS & 408 & 95.3 \\
\hline I don't know & 14 & 3.3 \\
\hline Common signs and symptoms of STI & & \\
\hline Foul smelling discharge & 112 & 26.2 \\
\hline Genital ulcer & 133 & 31.1 \\
\hline High grade fever & 136 & 31.8 \\
\hline No sign & 34 & 7.9 \\
\hline I don't know & 191 & 44.6 \\
\hline Modes of transmission of STDs. & & \\
\hline Unprotected sex & 331 & 77.3 \\
\hline Unsterilized sharps & 211 & 49.3 \\
\hline MTCT & 224 & 52.3 \\
\hline Contaminated blood & 229 & 53.5 \\
\hline I don't know & 29 & 6.8 \\
\hline
\end{tabular}

Prevention methods of STDs.

\begin{tabular}{lll}
\hline Abstinence & 250 & 58.4 \\
\hline Condom & 312 & 72.9 \\
\hline One to one & 237 & 55.4 \\
\hline Oral contraceptive pills & 128 & 29.9 \\
\hline Injectable & 99 & 23.1 \\
\hline I don't know & 31 & 7.2
\end{tabular}


Participants were also asked on the prevention methods of STIs, with responses condom (72.9\%), abstinence (58.4\%), one to one (55.4\%), oral contraceptive pills $(29.9 \%)$ and injectable $(23.1 \%)$. Less than one tenth $(7.2 \%)$ of the students were not able to identify any of the prevention methods.

\section{Knowledge of participants on contraceptives}

As described in table 3, most of the students $(93.7 \%)$ knew about the availability of contraceptives. When asked where contraceptive can be found, $57.7 \%$ of them responded from pharmacy, $57.2 \%$ from hospital $39.7 \%$ from clinic, $35 \%$ from regular shops, $12.6 \%$ from hotels and $11.9 \%$ were not able to identify where contraceptives can be found. The knowledge on any of the contraceptive methods was also assessed, in which the majority $65.7 \%$ responded condom followed by oral contraceptive pills $(50.7 \%)$, injectable (38.1\%), abstinence (32.5\%), withdrawal (7\%), IUD (4.4\%), Norplant (2.6\%) and 13.1\% said that they don't know. Participants were asked the best method of contraceptive they think and $53.3 \%$ replied that the best method they think is abstinence. Concerning to the best method of contraceptive in general, $53.5 \%$ of the participants answered abstinence followed by condom (20.6\%). They were also assessed for their knowledge of the best method of contraceptive during rape or unprotected sex and the majority (54\%) of the participants responded that they don't know, $28.5 \%$ said injection, $28.3 \%$ oral contraceptive pills, $3 \%$ Norplant and very few (1.9\%) said IUD.

\section{Table 3. Study participants' knowledge about contraceptives.}


Do you know the availability of contraceptives?

\begin{tabular}{ccc} 
Yes & 401 & 93.7 \\
\hline No & 27 & 6.3
\end{tabular}

Where can you find contraceptives?

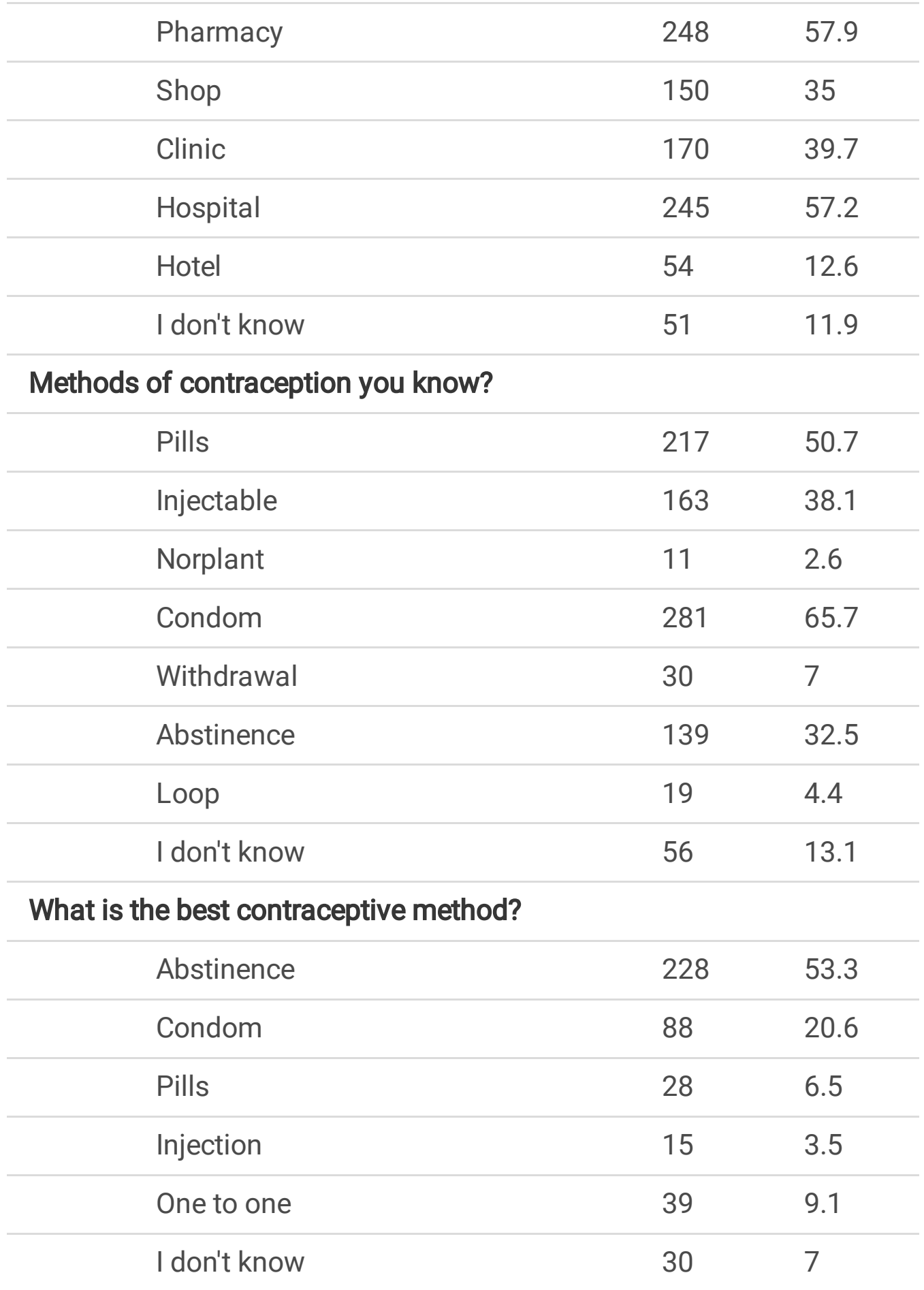

Best contraceptive during rape or unprotected sexual act

Injectable 


\begin{tabular}{lll} 
Pills & 121 & 28.3 \\
\hline Loop & 8 & 1.9 \\
\hline Norplant & 13 & 3 \\
\hline I don't know & 231 & 54
\end{tabular}

\section{Attitude of participants on reproductive health}

Regarding to the attitude of the participants on whether adolescents should get a regular reproductive health service and advice, 408(95.3\%) respondents had positive attitude. The result also showed that $333(77.8 \%)$ respondents had the perception that any adolescent can be infected with STIs. Moreover, $242(56.5 \%)$ of the respondents agreed that an adolescent need not to have a boyfriend or a girlfriend and $286(66.8 \%)$ had positive attitude towards continuing friendship with a friend who is infected with STI. The study also found that, 302(70.6\%) had the attitude that unmarried couple can use any types of contraceptive during sexual intercourse. Furthermore, 363(84.8\%) disagreed with sexual intercourse before marriage and $311(72.7 \%)$ reported pregnancy before marriage is not acceptable. Among the study subjects, $311(72.7 \%)$ stated utilizing sexually explicit material is not helpful (Table 4$)$.

Table 4. Mean (SD) and percentage distribution of the participant's attitude on RH. 
An adolescent boy or girl should get regular reproductive health service and advice?

$\begin{array}{lll}1.65 & 408 & 20(4.7) \\ (0.92) & (95.3) & \end{array}$

Any adolescent can be infected with sexually transmitted diseases?

An adolescent student needs not to have a boyfriend/girlfriend?

$3.14 \quad 242$

Continuing friendship with your friend who is infected with sexual transmitted disease has no problem?

$2.73 \quad 286$

Unmarried girl or boy can use any type of contraceptive during sexual intercourse?

$2.75 \quad 302$

Sexual intercourse before marriage is not acceptable?

Pregnancy before marriage is not acceptable?

\begin{tabular}{lll}
1.96 & 363 & 65 \\
$(1.31)$ & $(84.8)$ & $(15.2)$ \\
\hline 2.00 & 363 & 65 \\
$(1.26)$ & $(84.8)$ & $(15.2)$
\end{tabular}

Utilizing sexually explicit material is not helpful?

$\begin{array}{lll}2.48 & 311 & 117 \\ (1.50) & (72.7) & (27.3)\end{array}$

\section{Practice of participants on reproductive health}

Most (77.8\%) of the students stated that they did not have boy or girlfriend. Of those who had boy or girl friend, $3.5 \%$ were already engaged in sexual intercourse. The age of the respondents with regard to their engagement in sexual intercourse in descending order is that at age of $18(6.7 \%), 17(26.7 \%), 16(33.3 \%)$, $15(20 \%)$, and 14(13.3\%). Respondents who practiced sexual intercourse were at the mean age of 15.93 years (Table 5).

\section{Table 5. Study participants practice on reproductive health.}


Variables

Frequency Percent

Having boy or girl friend

\begin{tabular}{ccc}
\hline Yes & 95 & 22.2 \\
\hline No & 333 & 77.8
\end{tabular}

Engage in Sexual Intercourse

\begin{tabular}{lll}
\hline Yes & 15 & 3.5 \\
\hline No & 413 & 96.5 \\
\hline
\end{tabular}

Age at first intercourse

\begin{tabular}{lll}
\hline 14 & 2 & 13.3 \\
\hline 15 & 3 & 20 \\
\hline 16 & 5 & 33.3 \\
\hline 17 & 4 & 26.7 \\
\hline 18 & 1 & 6.7 \\
\hline
\end{tabular}

Using contraceptives during Sexual Intercourse

\begin{tabular}{|c|c|c|}
\hline Yes & 13 & 86.7 \\
\hline No & 2 & 13.3 \\
\hline \multicolumn{3}{|c|}{ Action to be taken when there is a sign of STI } \\
\hline Tell father & 179 & 41.8 \\
\hline Tell Mother & 244 & 57 \\
\hline Tell siblings & 119 & 27.8 \\
\hline Go to hospital & 339 & 79.2 \\
\hline Tell friends & 100 & 23.4 \\
\hline I keep quite & 20 & 4.7 \\
\hline
\end{tabular}

\section{Utilizing sexually explicit materials}

More than half (53\%) of the respondents said that they utilize sexually explicit materials and the majority $(63.9 \%)$ of them reported they use mobile phones, followed by video (35.7\%), internet $(24.7 \%)$, magazine $(18.5 \%)$ and sexual books (14.5\%). Most (53.3\%) of them started utilizing at the ages between 13 to 15 years, $42.3 \%$ at the ages between 16 to 18 years and a few (4\%) at the ages less than 12 years (Fig. 1 ). 


\section{Association of student variables with knowledge, attitude and practice}

Students in the age range 14 to 16 (mean \pm SD value of $19.45 \pm 6.12$ ) were found to have significantly higher level of knowledge than students in the age range 17 to 19 (mean \pm value of $17.60 \pm 5.81$ ) ( $p$ value $=0.048$ ). Moreover, the level of knowledge was significantly different among the three grades $(p=0.001)$. ANOVA (LSD post hoc) has revealed that grade eleven students had significantly higher level of knowledge than both ninth ( $\mathrm{MD}=2.72,95 \% \mathrm{Cl}: 1.28-4.17, p<0.001)$ and tenth grades $(\mathrm{MD}=2.08,95 \% \mathrm{Cl}$ : $0.57-3.59, p=0.007)$. Categories of gender $(p=0.876)$, religion $(p=0.942)$, ethnicity $(p=0.492)$, parent with whom did they grew up $(p=0.600)$, and with parent whom do they currently live $(p=0.692)$ did not show any statistically significant difference in the level of knowledge (Additional file 2).

As presented in additional file 3 , there is no statistically significant relationship the attitude of the students and their corresponding categories of demographic characteristics including age $(p=0.134)$, gender $(p=0.136)$, grade $(p=0.09)$, religion $(p=0.268)$, ethnicity $(p=0.494)$, with whom grew up $(p=0.604)$ and currently with whom they are living $(p=1)$.

The items of questions used to assess the practice of the respondents toward reproductive health were made in such a way where the ideal minimum and maximum scores are taken to be 0 and 10 . The distribution of the scores was not normally distributed and hence non-parametric statistics were used to assess the difference in the score of practice among the student categories. Mann-Whitney $U$ test revealed that those students who communicate with their parents on important issues were found to have higher level of practice $(p=0.039)$. However the rest of the variables such as age $(p=0.063)$, sex $(p=0.059)$, grade $(p=0.931)$, religion $(p=0.98)$, ethnicity $(p=0.327)$, with whom grew up $(p=0.362)$, currently with whom living $(p=0.703)$ and communication on important issues and pubertal changes were not found to be significantly related with the practice of the participants from a statistical point of view (additional file 4).

\section{Discussion}

Adolescents aged 19 years and below constitute the largest segment of the Eritrean population, that their health and wellbeing needs special considerations. However one of the major obstacles in designing age appropriate intervention is inadequate understanding about what adolescents already know, how accurate, practical and adequate their knowledge is. The focus of this study was therefore on the reproductive health knowledge, attitude and practice of adolescent high school students in Asmara, Eritrea. The median age of the study participants was $15(\mathrm{IQR}=2)$, in which $88.8 \%$ comprised those between 14 to 16 years old and considering their level of education, they were expected to have a better reproductive health knowledge. However, the findings reflected a low level of RH knowledge, with a potential risky behaviour that more than half of them were exposed to sexually explicit materials.

Reproductive health $(\mathrm{RH})$ is a crucial aspect and a reflection of general health during adolescence age. Adolescence, as a transition phase, is a period where such transition tended to be a more rapid event marked by the beginning of reproductive maturity $[1,23]$. More than five adolescent people are affected 
by reproductive health problems worldwide [24]. Thus, it is critically important that adolescents know the human reproductive physiology and methods of contraception to protect themselves from unwanted reproductive health problems [25]. In this study respondents were found with a very low level of knowledge related to reproductive physiology, in which only less than $50 \%$ of them new the average days of menstrual cycle and only $16.1 \%$ knew the time in which a woman is fertile and more likely to conceive. This finding is similar to previous national studies in which the knowledge about ovulation period was less than $17 \%[25,26]$. A much lowered level of knowledge (1.4\%) was reported in a similar study conducted in Saudi Arabia with more than two third of them having a poor knowledge regarding the types and methods of family planning [23].

Furthermore, in this current study, the level of knowledge regarding STIs, other than HIV was also low with comparable reports across other several similar studies [12, 23, 27].Three previous national LQAS surveys on HIV, RH and STIs reported that the comprehensive knowledge about HIV and STIs mode transmission, signs and symptoms and prevention methods was as low as less than $10 \%$ among the age groups of 1524 years $[17,28,29]$. Meanwhile, in this current study, most of the participants stated abstinence followed by use of condoms as methods of prevention form STIs and the level of knowledge regarding the ways of transmission of STIs was found higher than several other studies [4, 30, 31]. Regarding their sexual practice, from those adolescents who were already engaged in sexual practices $13.3 \%$ of the sexually active adolescents were exposed to unprotected sexual practice with the risk of exposure to unwanted pregnancy, illegal abortion and STIs including HIV/AIDS. Higher results were reported in a study form Nigeria in which $61.6 \%$ of the females and $27.8 \%$ of the females were engaged in sexual activity and of all these $81.4 \%$ of the males and $65.4 \%$ of the females were using contraceptives [32]. Moreover, a study from a neighboring country, Ethiopia stated $22 \%$ of the study participants were engaged in sexual relationships of which only $38.6 \%$ were using contraceptive methods and the remaining $61.4 \%$ were exposed to unprotected sexual practice [33]. In this current study, most of the study participants indicated that they perceive themselves as they are at the age of getting infected by HIV or STI and almost all of them (95.3\%) stated that they need RH information and services. Similar results were also reported by Adera et al 2013 , in which $92 \%$ of the study participants felt that they are susceptible to be infected by HIV or STIs. It is believed that such a result could be associated with the improved awareness from the consistent HIV/AIDS related campaign in the country. Meanwhile, the study from Saudi Arabian stated only $55.4 \%$ of the participants were found with a positive attitude towards reproductive health service services and advices. Such a difference could be attributed to the high influence of religious and social norms.

Knowledge and healthy behaviour are associated with each other. The WHO KAP model asserts that a person's knowledge prompts a behavioural change and a change in knowledge also brings a change in attitude. Normally, the level of knowledge on reproductive health is expected to increase with age which is associated with higher education level and increased life experiences. In this current study, students in grade eleven were found with the highest score of knowledge. Adolescents who get pressured by their peers and by the traditional societal values and beliefs get an unreliable information of sexuality, thus they are compounded by risk taking behaviours. Therefore, adolescence is a period which needs or 
requires a close and open family relationship, conducive school, work and neighbourhood environments, to help them to make good choices and shape their sexual behaviour and carrier development and finally fulfil their goal [34]. Two third of the participants from this current study have the attitude that any adolescent can get infected and were found with a positive attitude towards continuing friendship with a friend who is having STIs. Similar results were reported in the Ethiopian study in which $92 \%$ of the participants believed that they could get infected and $72 \%$ of them were positive towards continuing friendship with an affected friend [31].

Romantic relationships matter for adolescents. However, such relationships without having adequate knowledge about sexuality can introduce them risks to certain sexual health risks [35]. Earlier Eritrean studies $[25,36]$ have reported that dating among adolescents in this country was rampant. In this current study, almost half of them agreed for an adolescent to have a boy or girlfriend for a romantic heterosexual relationship and for the use of contraception, and practically $22.2 \%$ of them had a boy or girl friend. Likewise, $49 \%$ of the adolescents in a Nigerian study were found to agree with having a boy or girlfriend [37]. This can be more addressed in Life Skill training sessions which could help such adolescents in building healthy relationships. Meanwhile, almost all of them didn't agree with premarital sexual practice and only $3.5 \%$ of them had performed sexual intercourse, though it could possibly be masked as premarital sexual relationship is considered as a taboo as some contradictory attitudes were also observed [36]. A previous national study with participants from all regions of the country reported that all the discussants expressed their concerns on extramarital sexual relations among adolescents that it was high which was becoming a potential cause of unplanned pregnancies forcing families to arrange unplanned marriage and increase female school dropouts [36]. Similar results were also reported from a South African and Ethiopian studies in which $88 \%$ and $88.1 \%$ of their study participants were found with the attitude being against premarital sexual relationship respectively [38]. All these findings reflect that the cultural, religious and traditional believes and values of the African societies against extramarital sexual relationships. Meanwhile, in an African sociocultural context, where sexual intercourse out of marriage is a taboo and sexual acts and behaviours are masked, quantitative assessments need to supplement studies with a qualitative in-depth inquiry.

Several studies have shown that females are most of the time permissive in their relationship. They are more likely to engage in sexual behaviors to establish a relationship or to please a partner before they are emotionally ready. As reported from a study in Ghana, adolescent females described their first time having sex as necessary to prove their love to their partner or else have the risk of termination of the relationship [39]. Moreover, a study from Filipino reported, $23 \%$ of the adolescent study participants sampled nationwide were engaged in premarital sexual relationship [40]. Early initiation of sexual activity and the non-usage of contraception could have influenced the increased prevalence of premarital pregnancy and exposure to STIs which could also attribute to the societal burden [1]. This is the first study kind of its nature to examine adolescents' exposure to sexually explicit materials and its relationship with sexual attitude and behaviors. Exposure to sexually explicit material may be also be potentially harmful. It is associated with high risk sexual behaviors that have the potential to adversely affect reproductive health [41]. Some studies suggest that prolonged exposure to pornography can lead 
to exaggerated beliefs of sexual activity among peers, sexually permissive attitudes and sexual callousness [42] including more negative attitudes toward sexual partners with negative consequence of sexual experience and they can even accept casual sex [42, 43]. Although media can provide positive messages, some of the contents may be distorted and could be potentially harmful leading to the negative consequence. Higher perceived reality of pornographic content, and more frequent SEM usage were predictive of a higher likelihood of participants' sexual experience [44, 45]. In this current study even though $73 \%$ of them reported that watching pornographic video is not helpful, in practice more than half of them (53\%) started it earlier. Internet and magazine availability is very limited, thus the main source of the pornographic videos or pictures is mobile phone devices through which the adolescents share the videos among each other and this can be changed into an opportunity to reach the adolescents on their handsets with evidence based facts in different formats. A Tanzanian study stated magazine as the main source [46]. Moreover, a study from Ethiopia reported that, among the high school female students, $30.8 \%$ reported pre-marital sexual debut in which the major associated factors were frequent watching of pornographic video and those who watched pornography two or more times a week were 10 times more likely to start pre-marital sexual practice [47]. It has been put forward that sexual references on television and movies may be key contributors to early sexual acts and may lead to negative attitudes toward condoms and contraception, having multiple sexual partners and teen pregnancy [48-50]. Furthermore, females who were exposed to pornographic movies were more likely to have more sexual partners and to have a negative attitude toward condoms [50]. Providing adolescents with a small amount of knowledge regarding the effects of media can improve adolescent health [48].

A study from Ghana reported that the introduction of reproductive health campaigns have raised the knowledge of the adolescents in which more than $90 \%$ of them were able to mention at least one modern method of family planning [1]. Moreover, studies indicate that more knowledge leads to less reproductive health problems. Sexual education is found to be the most useful way to reduce problems associated with sexual practice as it educates adolescents on safe sexual practice, abstinence and contraceptive use. Also it makes them become more responsible in making decisions about their life [20].

\section{Limitation of the study}

This study was based on cross-sectional data, which implies that the direction of causal relationships cannot always be determined. The findings of the study are not based on nationally representative sample, so that generalizations cannot be made. A clear definition of sexually explicit material couldn't also be made as the content and definition was up to the discretion of the participants.

\section{Conclusions}

The findings related to adolescent's knowledge and practices in the fields of sexuality and reproductive health $(\mathrm{RH})$ showed low scores in almost all variables of the study. Despite their lack in RH knowledge a significant number of students are already engaged in heterosexual romantic relationships. Moreover high number of the students watch pornography almost daily and they share the sexually explicit 
materials through their smart phones. Schools should provide knowledge on sex education, media to the extent which can guild the adolescents. Parents can also play an important role in guiding adolescents to positive attitude and behavior. Adolescents need to be knowledgeable about themselves and the people they relate to, need sound information about the physical, psychological and social changes that take place through childhood to adolescence. The sexually explicit materials may also serve as an educational purpose and create an opportunity to engage adolescents in a complete, honest discussion about sexual health and informed consumption of information. Governments and other stakeholders have the responsibility of developing programmes that provide adolescents with accurate information to enable them to have a desirable control over issues pertaining to reproductive health.

\section{Abbreviations}

ANOVA: Analysis of Variance; FDG: Focused Group Discussion; HIV/AIDS: Human immunodeficiency virus/Acquired Immune Deficiency Syndrome; IQR: Interquartile range; IUD: Intrauterine device; LQAS: Lot Assurance Sampling; LSD: Least Significant Difference; $\mathrm{MOH}$ : Ministry of Health; RH: Reproductive health; SD: Standard Deviation; SPSS: Statistical Package for the Social Sciences; SSA: Sub-Saharan Africa; STI: Sexually Transmitted Infection; SRH: Sexual and Reproductive Health; WHO: World Health Organization

\section{Declarations}

\section{Ethics approval and consent to participate}

Ethical clearance and approval were obtained from the ethical and scientific committee of the Asmara College of health Sciences as well as from the Health Research Proposal Review and Ethical Committee of the Ministry of Health. Permission was also secured form for the Ministry of Education and from the directors of all the selected high schools. After explaining the purpose of the study and assurance of confidentiality and anonymity, informed written consent was obtained from each participant and they were told that their participation is voluntary and they can withdraw at any stage the study. For those who were under the age of 18 years, consent was obtained from the responsible guardians.

\section{Consent for publication}

Not applicable.

\section{Availability of data and materials}

The datasets generated and/or analyzed during the current study are available from the corresponding author on a reasonable request.

\section{Competing interests}

The authors declare that there are no any competing interests. 


\section{Funding}

No Funding

\section{Authors' contributions}

YMA: Data analysis and interpretation, drafting and revising the manuscript for important intellectual content, and submission of manuscript; GGW: Study conception and design of study, acquisition of data, analysis and interpretation of data, revising the manuscript critically for important intellectual content; BZB: Study conception and design of study, acquisition of data, analysis and interpretation of data; EGG: Study conception and design of study, acquisition of data, analysis and interpretation of data; GHG: Study conception and design of study, acquisition of data, analysis and interpretation of data; TYG: Study conception and design of study, acquisition of data, analysis and interpretation of data.

\section{Acknowledgements}

The authors would like to thank the study participants for their support.

\section{References}

1. Simona, R. and K. John, Knowledge, attitude and practices on Reproductive Health. African Journal of Reproductive Health, 2009. 13(4).

2. Lerner, R.M., et al., Understanding developmental systems in adolescence: Implications for methodological strategies, data analytic approaches, and training. Journal of Adolescent Research, 2001. 16(1): p. 9-27.

3. Giedd, J.N., The digital revolution and adolescent brain evolution. Journal of Adolescent Health, 2012. 51(2): p. 101-105.

4. Peter, H., Assessment of knowledge on reproductive health among adolescents attending secondary schools in Moshi Municipality of Kilimanjaro, Tanzania. 2013, The Open University of Tanzania.

5. Guttmacher Institute, Facts on Adolescent Women in the Developing World, 2010, http://www.guttmacher.org/pubs/FB-Adolescents-SRH (Accessed September 2018). .

6. Dornbusch, S.M., Transitions from adolescence: A discussion of seven articles. Journal of Adolescent Research, 2000. 15(1): p. 173-177.

7. Kassa, G.M., et al., Prevalence and determinants of adolescent pregnancy in Africa: a systematic review and meta-analysis. Reproductive health, 2018. 15(1): p. 195.

8. Muhwezi, W.W., et al., Perceptions and experiences of adolescents, parents and school administrators regarding adolescent-parent communication on sexual and reproductive health issues in urban and rural Uganda. Reproductive health, 2015. 12(1): p. 110.

9. Hailay Gebreyesus, Mebrahtu Teweldemedhin and Abebe Mamo. Determinants of reproductive health services utilization among rural female adolescents in Asgede-Tsimbla district Northern Ethiopia: a 
community based cross-sectional study. Reproductive Health, 2019. 16:4 https://doi.org/10.1186/s12978-019-0664-2

10. Gebreyesus, H., M. Teweldemedhin, and A. Mamo, Determinants of reproductive health services utilization among rural female adolescents in Asgede-Tsimbla district Northern Ethiopia: a community based cross-sectional study. Reproductive Health, 2019. 16(1): p. 1-10.

11. Kirby, D.B., B. Laris, and L.A. Rolleri, Sex and HIV education programs: their impact on sexual behaviors of young people throughout the world. Journal of adolescent Health, 2007. 40(3): p. 206217.

12. Newton-Levinson, A., J.S. Leichliter, and V. Chandra-Mouli, Sexually transmitted infection services for adolescents and youth in low-and middle-income countries: perceived and experienced barriers to accessing care. Journal of Adolescent Health, 2016. 59(1): p. 7-16.

13. Chandra-Mouli, V., et al., Contraception for adolescents in low and middle income countries: needs, barriers, and access. Reproductive health, 2014. 11(1): p. 1.

14. Gebremicheal, A., et al., Comprehensive Study on the Nature, Root Causes, and Extent of the Health and Social Problems for Adolescents in and out of School in Eritrea. 2012, Asmara: Ministry of Health Eritrea.

15. Eritrean Health and Population Survey (EHPS), Asmara, Eritrea, 2013 pp 35.52, 2010.

16. Ghebreyohans, G., et al., The effect of peer education on peer educators' reproductive health knowledge, attitude, health service use and their personal development. International Journal of Sciences: Basic and Applied Research, 2015. 20(1): p. 294-312.

17. Lots Quality Assurance Survey on Reproductive Health performance Survey (LQAS), Ministry of Health, Asmara, Eritrea, 2013.

18. Lots Quality Assurance Survey on Reproductive Health performance Survey (LQAS), Ministry of Health, Asmara, Eritrea, 2017.

19. Lots Quality Assurance Survey on Reproductive Health performance Survey (LQAS) Ministry of Health, Asmara, Eritrea, 2019.

20. Khoza, L., Adolescents' knowledge, beliefs and experiences regarding sexual practices. Health SA Gesondheid, 2004. 9(3): p. 34-41.

21. International Conference on population and development, Cairo, Egypt, 1994.

22. Ministry of Education Head Office, Department of Human Resource, Asmara, Eritrea, 2018-2019.

23. Gaferi, S.M., et al., Knowledge, attitude and practice related to reproductive health among female adolescents. Journal of Nursing Education and Practice, 2018. 8(8): p. 53-65.

24. Eaton, L., A.J. Flisher, and L.E. Aarø, Unsafe sexual behaviour in South African youth. Social science \& medicine, 2003. 56(1): p. 149-165.

25. Ghebreyohans, G., et al., Peer Reproductive Health Education Trial in Eritrea.

26. Eritrean, Health and Population Survey (EHPS), Ministry of Health, Asmara, Eritrea, 2010. 
27. Bankole, A., et al., Sexual behavior, knowledge and information sources of very young adolescents in four sub-Saharan African countries. African journal of reproductive health, 2007. 11(3): p. 28.

28. Lots Quality Assurance Survey (LQAS) on Reproductive Performance of Department of CDC Ministry of Health, Asmara, Eritrea, 2017.

29. Lots Quality Assurance Survey (LQAS) on Reproductive Performance of Department of CDC Ministry of Health, Asmara, Eritrea, 2019.

30. Das, B. and G.J. Desai, KAP study of reproductive health and sexually transmitted diseases among high school girls of Vadodara city. Int J Med Sci Public Health, 2016. 5(3): p. 412-5.

31. Adera, A., et al., Assessment of knowledge, attitude and practice of students towards sexual transmitted infection in Haile Mariam Mamo preparatory school Debre Birhan, Ethiopia. Science Journal of Public Health, 2015. 3(4): p. 563-71.

32. Oni, T., et al., High school students' attitudes, practices and knowledge of contraception in Jozini, KwaZulu-Natal. South African Family Practice, 2005. 47(6): p. 54-57.

33. Kibret, M., Reproductive health knowledge, attitude and practice among high school students in Bahir Dar, Ethiopia. African journal of reproductive health, 2003: p. 39-45.

34. Qin, D.B., et al., "My Culture Helps Me Make Good Decisions" Cultural Adaptation of Sudanese Refugee Emerging Adults. Journal of Adolescent Research, 2015. 30(2): p. 213-243.

35. Kerpelman, J.L., et al., Evaluation of a statewide youth-focused relationships education curriculum. Journal of Adolescence, 2009. 32(6): p. 1359-1370.

36. Ghebreyohans, G., et al., Burden of Reproductive Health Illiteracy in Eritrea. International Journal of Sciences: Basic and Applied Research (IJSBAR), 2015. 19: p. 285-297.

37. Idowu, A., et al., Knowledge, attitude and practice of contraception by female junior secondary school students in an urban community of Oyo-state, South west, Nigeria. Int J Reprod Contracept Obstet Gynecol, 2017. 6(4759): p. 2320-1770.

38. Gashaw, A., et al., Low prevalence of HIV infection, and knowledge, attitude and practice on HIV/AIDS among high school students in Gondar, Northwest Ethiopia. Ethiop J Health Dev, 2007. 21(2): p. 179182.

39. Rokicki, S. and G. Fink, Assessing the reach and effectiveness of mHealth: evidence from a reproductive health program for adolescent girls in Ghana. BMC public health, 2017. 17(1): p. 969.

40. Serquina-Ramiro, L., Physical intimacy and sexual coercion among adolescent intimate partners in the Philippines. Journal of adolescent Research, 2005. 20(4): p. 476-496.

41. Braun-Courville, D.K. and M. Rojas, Exposure to sexually explicit web sites and adolescent sexual attitudes and behaviors. Journal of adolescent health, 2009. 45(2): p. 156-162.

42. Zillmann, D. and J. Bryant, Effects of massive exposure to pornography, in Pornography and sexual aggression. 1984, Elsevier. p. 115-138.

43. Roberts, T.A., P. Auinger, and J.D. Klein, Intimate partner abuse and the reproductive health of sexually active female adolescents. Journal of adolescent health, 2005. 36(5): p. 380-385. 
44. Tomić, I., J. Burić, and A. Štulhofer, Associations between Croatian adolescents' use of sexually explicit material and sexual behavior: does parental monitoring play a role? Archives of sexual behavior, 2018. 47(6): p. 1881-1893.

45. Mattebo, M., et al., Pornography consumption among adolescent girls in Sweden. The European Journal of Contraception \& Reproductive Health Care, 2016. 21(4): p. 295-302.

46. Mahega, A.G., Media and sexual behaviour of secondary school students: a case of Arusha municipality. 2014, Sokoine University of Agriculture.

47. Mulugeta, Y. and Y. Berhane, Factors associated with pre-marital sexual debut among unmarried high school female students in bahir Dar town, Ethiopia: cross-sectional study. Reproductive health, 2014. 11(1): p. 40.

48. Brown, J.D. and P.S. Bobkowski, Older and newer media: Patterns of use and effects on adolescents' health and well-being. Journal of Research on Adolescence, 2011. 21(1): p. 95-113.

49. Collins, R.L., S. Martino, and R. Shaw, Influence of new media on adolescent sexual health. 2010, Working Paper WR-761). Santa Monica, CA: Rand Health.

50. Wingood, G.M., et al., Exposure to X-rated movies and adolescents' sexual and contraceptive-related attitudes and behaviors. Pediatrics, 2001. 107(5): p. 1116-1119.

\section{Figures}

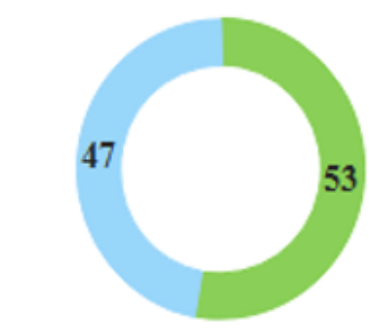

Utilize sexually explicit material

Do not utilize secxually explicit material

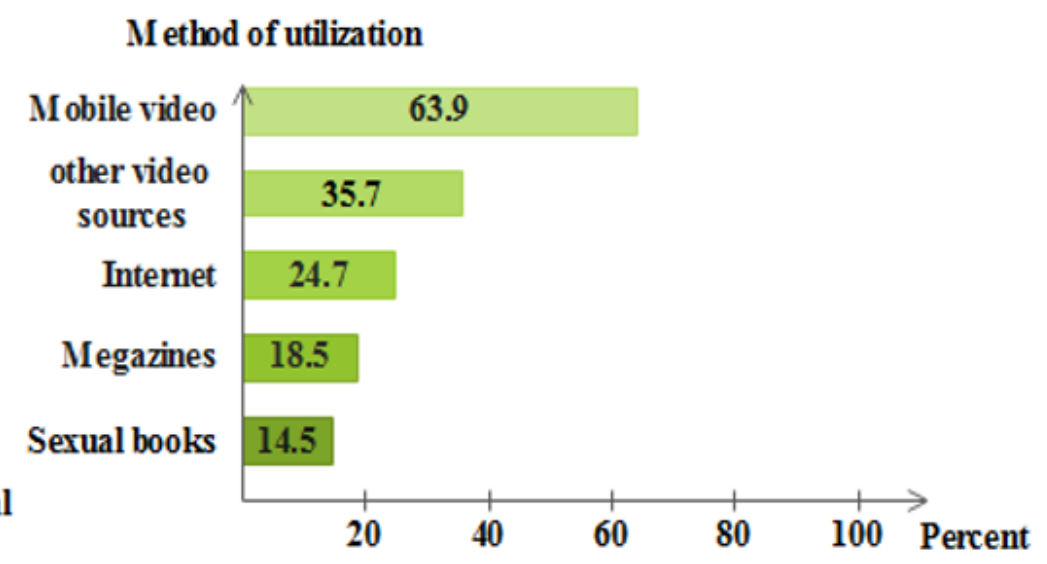




\section{Figure 1}

Percent distribution of students who utilize sexually explicit material, the material they use and the age at which they start utilizing.

\section{Supplementary Files}

This is a list of supplementary files associated with this preprint. Click to download.

- Additionalfile1.docx

- Additionalfile2.docx

- Additionalfile3.docx

- Additionalfile4.docx 